\title{
The contribution of volunteering,
}

\section{trust and networks to educational}

\section{performance}

\begin{abstract}
Social capital can have a beneficial effect on public policy outcomes by helping to solve collective action problems and by providing individuals and communities with efficient social networks. In education it also assists students' self-confidence, which can foster motivation and academic success. To investigate the social capital-outcome link, this article analyses a panel survey of 15-16 and 16-17 year-olds in 27 English schools, testing whether social capital, both at the individual and at the school levels, tends to increase grades and examination performance. The analysis concludes that individual-level trust and voluntary action improve pupil performance, but that the parental networks of some young people, particular those from low-SES families, have negative rather than positive consequences. The findings add to a debate about the differential impact of social capital and the relative importance of its bridging and its bonding elements.
\end{abstract}

Key words: education, social capital, trust, volunteering, parental networks 


\section{Introduction}

It is rare for policy-makers and experts to desire social capital for its intrinsic qualities. Though some desire to return to a 'golden age' of high levels of public trust and greater participation in public affairs, most elites and experts think that social capital is desirable because of its effects on the outcomes that citizens and governments care about - making what counts as 'what works'. So in Making Democracy Work (1993) Putnam argues that social capital, in the form of associational memberships, improves the innovation and efficiency of regional governments, a piece of research that stimulated a burst of commentary and research on the impact of social capital on the workings of democracy. Then in Bowling Alone (2000), in answer to the question 'so what?', Putnam uses a broader definition of social capital - including networks and social trust - to highlight its positive effects on education, children's welfare, safety, economic prosperity, health and happiness. In addition to Putnam's work, a battery of evidence now shows the links between social capital and public policy outcomes (see the reviews by OECD 2002, PIU 2002), such as lower crime (Halpern 2001), economic growth (Whiteley 1990, Knack and Keefer 1997), and the performance of US states (Rice and Sumberg 1997). These accounts describe a complex causal story through which social capital improves individual well-being, reduces personal stress, and improves collective action through facilitating communication and the more efficient exchange of resources, and where a series of beneficial actions reinforce each other. But in spite of the positive research literature, there is a need for more concrete evidence about what exactly it is about social capital that works. A recent academic review of the state of social capital research lamented the lack of social science evidence upon which policy-makers can build (Sobel 2002). Moreover, recently there is more attention the 
differential effects of social capital, such as by ethnic group, processes that are not clearly understood (see Hero 2004, Usalner 2004)

This article seeks to fill just such a gap and offers findings about the differential impact of social capital with clear lessons for policy-makers. It extends the research field by examining a crucial site for the creation of public values - the school. Education's importance is underlined by the link between educational performance and a range of other desirable outcomes, such as economic growth and high employment. Moreover, schools can create or foster social capital directly, particularly because education is about the transmission of values and norms, as well as the inculcation of skills. If a clear link exists between social capital and policy performance, it would be tempting for policy-makers to alter aspects of school provision and management to foster the accumulation of social capital, perhaps as part of a program to increase public values and the practice of good citizenship, whilst recognizing that families and communities are the main drivers. The social capital pathway may be seen to be an alternative or complement to other explanation of student performance, such strengthening the bureaucracy (Meier et al 2000, Bhote 2005, Smith and Larimer 2004 ), the span of control (Bhote and Meier 2001), or more school choice (Schneider et al 2000).

\section{Theory}

So why does social capital matter in schools? Group membership is often thought to generate psychological benefits and to enhance the social skills students get from education. Typically group members have an extensive input in the running and choices of their group (Beck and Jennings 1982). This experience yields psychological benefits: adolescents gain self-esteem and feelings of control over their environment, which affects their motivation and hence their academic performance 
(Steinberg 1996, Smith 1999). Associational activities are generally thought to be a bridging form of social capital as members tend to meet others who are not like them, which has positive payoffs for personal development. More generally, voluntary memberships are thought to foster a sense of obligation and responsibility, which may affect educational outcomes by students applying themselves more effectively in homework and in class.

The second aspect of social capital is trust, which can sustain interactions in the wider society, assist social co-operation and help provide local solutions to collective action dilemmas. It has beneficial consequences because it lowers the costs of transactions in society and in the economy. In the context of the school, more trusting students may be more willing to take cues and information from their instructors, have a more positive orientation to academic study and solve learning problems collectively.

Linked to these causal pathways, but which involves a separate process, is the operation of networks that confer advantages on those in them by the enforcement of helpful norms and transmission of useful information if these exist. The network process has now become regarded a general benefit in the production of public goods (Milward and Provan 2000). Networks deliver a range of useful outcomes, usually to do with coordination and information transfer, but also trust and faith in procedural fairness (Schneider et al 2003). Network benefits have particular application to the education sector, as shown by analysis of the Texas school district data in a series of important studies (Meier and O’Toole 2001, 2004, 2005).

At the student level, there is a line of research that examines the impact of peer groups on performance, with some studies finding a positive impact for students in class based networks whereas more isolated students perform less well (Nicols and White 2001). Many studies of social capital and education focus on the family in the way in which supportive relationships that surround 
parents and children, in the form of family social capital, assist performance (Valenzuela and Dornbusch 1994). In the classic formulation of Coleman and his co-researchers (Coleman, Hoffer and Kilgore 1982a; Coleman and Hoffer 1987), the different rates of success for minorities in the US is attributed to the higher levels of social capital in the communities of Catholic schools, largely because of close social networks and shared values. Though supported by studies of US schools (e.g. Sandler 1996), subsequent research questions whether these networks translate into improved outcomes and considers the impact of other factors associated with Catholic schools (Morgan and Sørensen 1999). It may be the case that the networks around schools are based on close associations of parents who are like each other and where positive ideas about learning are not transmitted. The question these two literatures pose is whether networks are a form of bonding social capital, that is a dense set of relationships that have psychological benefits for their members, which may turn into good performance; or are in fact the more desirable bridging form. Bridging social capital involves links between social groups and promotes the exchange of information and learning from others. What Granovetter’s (1973) termed ‘weak' ties matter - or add ‘strength' - because they allow individuals to access resources outside their immediate and close networks, though the data in one Dutch study examining peer groups and delinquent behavior do not support this finding, with adolescents with wider networks having a greater tendency to be delinquent (Baerveldt et al 2003).

To investigate the effects of social capital upon performance, the analysis needs theory and prior empirical evidence to produce suitable controls in statistical models. There are several 'usual suspects' to include: individual socio-economic status (SES) because education performance is transmitted across the generations through the family and local environments (Coleman et al 1966). Similarly, students' attitudes to education, such as willingness to stay on in it, are drawn from their parents, who may encourage their children and provide role models. Ethnicity and gender are also 
essential controls, though the literature disagrees as to the extent of the effects and, for gender, in which direction (e.g. see Linn and Hyde 1989, Arnot 1998). Another background variable, which is part parental, part school-influenced and part individual, is religious background (Lehrer 1999, Regnerus and Elder 2001).

Performance may be also be predicted by the cognitive-styles of young people. The hypothesis is that adolescents may discount the future in different ways, i.e. some are prepared to wait for future benefits (Mischell 1958, 1960), which, in the context of academic performance, is the recognition that the benefits from hard work in school are some way off. It is also important to take account of parental involvement (Ho and Willms 1996) and the climate of schools, such as the extent of teacher co-operation (Kreft 1993, Ashworth 1995). In addition, it is correct to assume that the type of school affects performance, in particular draw on Coleman et al's (1982b) inference that private schools increase performance because of their ethos and/or particular selection criteria. Finally, television watching can worsen performance because it affects cognitive development (Anderson and Collins 1988).

\section{Measurement and Conceptual Issues}

Social capital presents a number of challenges in survey research. The first is the familiar one of definition. Researchers may follow the Tocquevillian route of regarding associations as the key mechanism at work; others may choose trust or social networks. These elements are often contained in the same literature, though authors tend to concentrate on one, without losing sight of the others, such as Putnam's (2000) focus on group membership and networks. But the researcher faces the problem of which measure to use, especially as the mechanism for affecting outcomes is rather different in each one. Fortunately, in the case of the open concept of social capital, it is better 
to be pluralistic and use several definitions and measurement, and let hypothesis testing find out which are the significant factors, making the research question about what kinds of social capital promote better outcomes rather than assuming it is the totality of it that matters. In any case, the differential impact has been noted in some in some research with some studies finding that trust causes better outcomes, such as economic growth (Whiteley 1990), and others concluding that membership of organizations is not efficacious (Knack and Keefer 1997). A strategy of combining these measures or concentrating on one would miss out on this possibility of adjudicating between different types of social capital, such as between bridging and bonding. The measures are also highly connected as association membership and networks are linked to (though do not necessarily cause) social trust (Stolle 2001, Hooghe and Stolle 2002), with networks and associations needing some trust to begin with (Usalaner 2001). Thus it is possible to test hypotheses about the relationship between different sorts of social capital and academic performance.

The second problem is to understand how social capital operates at the individual and collective levels. Some writers, such as Coleman and Putnam, argue that social capital is a property of social structures, which societies have developed, usually through social institutions, over many decades. It is not individuals on their own who develop socially productive goods that help themselves, but by acting together they create social clusters of activity to produce social goods. Yet the collective dimension is generated individually, and can be partly consumed individually too. Thus academic performance may be generated by the activities of students and their families, enhanced by the characteristics of the school and the collective actions of parents, and consumed partly individually and partly collectively because improved educational outcomes benefit societies as well as, if differentially, the individuals. Recent research takes on board the different levels of analysis, such as Sun’s (1999) deployment of an aggregate measure - community-based social 
capital - to predict educational performance used alongside the individual-level variables. Thus by creating a measure for a larger unit, such as a school, data analysis can test the hypothesis that performance may be affected by a peer effect of social capital as well as the individual impact.

Third, there is a large debate as to whether the impact of social capital is necessarily positive. Critics of social capital sometimes say that social capital may lead to negative outcomes, such as the dense networks and trust that operate among the Mafia for example (Gambetta 1993). This does not pose a problem with research, however, as social capital is not a truism, but a hypothesis.

Researchers can hypothesize that in certain circumstances, such as among certain social groups, the social capital effects of bonding social capital can be negative without undermining the claims that in other circumstances the effects are positive.

Finally, education performance itself presents problems of definition and measurement. Educational outcomes extend from the role of schools in raising attainment levels, to enhancing individual capacity in a variety of non-academic areas to giving benefits to the wider society and economy, and may be observed at the individual, school and community levels. This article mainly focuses on academic attainment at the individual level, whilst paying attention to school-level effects.

\section{Data, Variable Definitions, and Methods}

Sampling

During the fall of 2000 the project surveyed 15-16 year olds at the start of their final year before a key set of examinations, GCSEs, - the General Certificate of Secondary Education. ${ }^{1}$ GCSEs are the main qualifications for 15-16 year-olds in England, a set of separate subject-related examinations on mathematics, biology, English language and so, which are graded from A to E, and

1 The data has been archived at the University of Essex, Hhttp://www.data-archive.ac.uk/H, Study Number 4982. 
where the grades A, B, and C are the passes, and which are essential for the job market or for access to the next stage of education. The age group is important because 16 is the last year of compulsory school education in the UK, so these students face important choices about what to do next in their lives. The sample schools were chosen from the large sub-national government area of Hertfordshire because its large size of just over a million inhabitants. The area offered a range of neighborhoods - from scattered villages to the urban outer-London - and a variety of social environments, including some of the most deprived areas in Britain. Having identified the study site, the next task was to choose the sample. The project recruited twenty-four state schools selected according to a stratified sample based on social intake, quality (examination performance), and according to the extent of provision of 'citizenship-type' activities and as well as how much citizenship was taught. ${ }^{2}$ The schools were sorted into eight groups on each of the criteria and those at the top, bottom and middle of each group were chosen. The study also included three fee-paying or private schools, which were selected by the same process, except that the level of fees was substituted as one of the selection criteria.

\section{Project Administration}

The research team sought permission to administer a self-completion questionnaire to 1,249 students who were in year 11 of their schooling in the sample schools (aged 15-16). After extensive piloting and local educational authority input, the questionnaire was made appropriate for all ability groups and depended mostly on tick-box responses. It took around twenty minutes to complete and was conducted in general studies classes or their equivalent. As the whole of the year was present the study achieved a near 100 per cent response rate for the year group. In all but one case, a

\footnotetext{
${ }^{2}$. Proportion of pupils in receipt of free school meal, ranked provided by the education authority. Examination (GCSE) data was gathered from Secondary School Performance Tables for 1999. Citizenship practice data was gathered from all schools (that is secondary, special, pupil referral units and independent schools) by means of a two-sided A4 questionnaire, which was sent to head teachers in the summer term of 2000.
} 
member of the research team was present to answer questions and to ensure that responses were not seen or guided by teachers. The researchers assured all respondents that their responses were confidential to the project. Approximately one year after the first wave, the project re-surveyed the young people by a postal questionnaire sent to their home addresses, which had been gathered in the first phase, achieving a 60 per cent response rate from year one. The panel data allows the exploration of changes in attitudes and behavior over time, but also gives outcomes data relevant to social capital and education. Specifically, wave two gathered the GCSE examination results.

\section{The Measurement of Academic Performance}

Wave one of the survey measures academic proficiency as reported by the students on a scale from low (1) to high (5) as the survey took place before the main examinations student take at aged sixteen. The following year's survey was able to pose questions on these examination results rather than reported grades. Wave two asked for passes at GCSE. These measures are the response variables, both for each wave and for the panel. The number of passes correlates highly with the self-reported grades (Pearson=.69, sig at p.<.001). The school average of this survey report has a good relationship (Pearson=.431, p. $<.05$ ) to the officially measured school-level examination results, the per cent of year 11 students with GCSE passes. ${ }^{3}$ It can also be assured that the students did not over report their exam results as the school average from the survey is lower than official school average. In addition, the analysis carried out a separate set of regressions on the school data (aggregating the social capital variables and plotting and regressing them on the officially measured results) to confirm the individual-level results.

It is not possible to combine the raw self-report scores in the panel models because they are measured differently in each wave, so both are standardized before amalgamating. The descriptive

\footnotetext{
3 Individual-level results are not available for researchers to use in England
} 
statistics of these and the control variables are contained in Table 1. More detail about these and other variables’ coding appears in the appendix.

\section{Social Capital}

Social capital is measured in three ways: networks amongst the parents, networks/associational activity of students and trust. The parental network term is students’ response to a question that asked about the extent to which they perceive their parents socializing with their friend's parents, which ranges from zero to ‘very occasionally’ (2), 'not very often’ (3) and 'very often' (4), which may be regarded as a bonding form of social capital. The trust variable adds together the responses to questions that ascribe of trust of neighbors, adults in the school and students in their class, each of which takes the values of 'not at all' (0), 'not very much' (1), 'quite a lot' (3), and 'a great deal' (4), which indicates bridging social capital as it asked students to say how they trust others outside their group. We do not use a summary score here as the measurement is of the level of trust rather than an underlying measure. ${ }^{4}$ Group membership takes values from 0 to 8 by adding the yes scores to ten questions about whether students had carried out one of different kinds of voluntary activity: fundraising, petitions, rangers, religious projects, election campaigns, helping elderly, environmental projects, charities, demonstrations and other voluntary activities. This is again an additive rather than an underlying score. These questions were asked in both waves, which means that both performance and social capital vary across the panel. In addition, there are corresponding school-level social capital variables, which are created by aggregating and averaging for each school the individual-level scores for social networks, trust and volunteering.

\footnotetext{
${ }^{4}$ Alternative methods of scaling the variable do not substantively affect the results.
} 


\section{Control Variables}

SES is measured by the number of cars or vans reported to be in the household and a dummy variable based on whether the place the student lives is owned by their family or not (most homes in the UK are owned and if they are not, they are distinctive, such as in council housing estates or housing association blocks and thus well known to the students whilst the private rental sector is miniscule). This underlying variable is represented by a summary score - the sum of the unstantandardized individual item scores (alpha=.45), which is a standard method of scaling variables in education survey research and is similar to other methods of representing an underlying variable, such as saving a score from an extraction using principal components. Parental education is measured as a dummy variable based on the students' recollection of whether the parent went to university or to a polytechnic, which is a big social distinction in the UK and likely to be known by 16-17-year olds. The definition of ethnicity adds together different non-white ethnic groups because of the relatively small numbers of the ethnic minorities in the population outside London, which is reflected in the sample. The religion dummy variable measures whether the student is Protestant, Jewish, Catholic or of another religion, or whether no religion is indicated. The discount rate question asks (adjusting to current sums of money) the classic question as to whether the respondent wants $£ 100$ right now at value of zero or would rather wait one whole month and get $£ 150$ coded at one. In addition, the survey measured the number of hours students reported watching television.

The measure of parental involvement is based on students' recollection that their parents come to parents' evenings and to fundraising activities, which is the sum of the individual item scores (alpha=.47). School management factors are whether students think their teachers work well or badly together, whether teachers invite the expression of opinions, how much say they have in class and how much they are consulted about school rules. Given the similarity of these variables 
(alpha=.48), another summary variable represents school climate. Finally, a dummy variable indicates the private as opposed to the state schools in the data. Most of these variables do not vary over the waves so were measured just once in wave one. The exception was the hours watching television where the same question was posed in both waves one and two. Table $1 \mathrm{~b}$ contains the descriptive statistics for these variables.

\section{Data Properties}

The analysis seeks to determine the impact of these individual-level measures on public policy outcomes. But the data do not just refer to students randomly sampled, but to those who are 'nested' within schools. The data is hierarchical, with two levels of analysis - schools and students. Thus multilevel modeling is appropriate to generate the estimates (Goldstein 1995, Kreft and Leeuw 1998, Hox 2002), a procedure that is common in education research (e.g. Goldstein et al 1993, Kreft 1993). Multilevel models seek to estimate equations when the units are clustered, usually into spatial locations, which means there are different distributions of errors at each level. As a result of these data properties, one of the key assumptions of ordinary least squares and other forms of regression, independence, may be broken. Multilevel models explicitly model the grouping of individuals into groups. The estimates avoid underestimating the standard errors and creating incorrectly specified models; they also allow the exploration of the unit of interest in this study - in this case the school. The models presented here have explanatory variables that define the fixed and random parts of the model, which allows the coefficients for the social capital terms to vary across units at one or more levels, which has the added advantage of reducing the possibility of unobserved heterogeneity and increasing the specification of the models. 


\section{The Estimator}

The estimates are generated by a modified Newton Raphson algorithm and an adaptive quadrature procedure (Rabe-Hesketh et al 2004, www.gllamm.org). Adaptive quadrature is a numerical procedure for determining density under a curve, which was developed before the use of hand calculators, but which has been speeded up with advanced computing. The algorithm makes an initial calculation of the density, and its the accuracy is tested by comparing the results according to the rules. If the test fails, the integration range is split (typically in half) and the rules applied to each section. This process is repeated until convergence is achieved. Experimental research suggests that this procedure is superior to the more standard Gaussian method, such as those used in two-level generalized linear models, especially if there are a large number of level-1 units (Rabe-Hesketh et al 2002).

\section{The Panel Design}

Of particular importance is the contribution of the panel to making the overall inference as reported in Table 4. A key problem with research on social capital is the effective identification of the causal arrow. It may be the case that individuals who achieve more also join groups and trust more. This problem is caused by selection, which affects social capital research acutely. Social capital is associated with or is the consequence of individual characteristics, which also cause socially beneficial outcomes. Typically researchers use surveys that make observations at one period of time, where researchers cannot always adjudicate on the direction of causation. But panel data, such as the one used here where the same measures vary over two time periods, can trace the causal processes, as it is less likely to observe selection with both increases in social capital and academic achievement occurring at the same time. The possibility that a hidden variable determines both achievement and social capital is limited because all the theoretically derived relevant factors 
are controlled at two time periods. The models predict changes in performance from a dataset that stacks the cases over the two waves, allowing the critical variables to vary both within the wave and across the time periods.

In addition, a multilevel research panel research design can help eliminate unobserved heterogeneity at the school level, which also varies across the time period. Controlling for the aggregate level of social capital in each school in both time periods soaks up peer effects as well as being a separate hypothesis. In addition, it is possible to control for exogenous change over the panel through a further variable, time, that takes the value of zero in wave one and one in wave two.

\section{Results and Discussion}

\section{Wave One}

The first two models in table 2 produce the estimates of self-reported academic proficiency for wave one: model 1 uses just the individual level terms and model 2 adds in the aggregated scores. Model 1 shows most of the variables performing as expected whilst others acting as necessary controls. The SES term is not significant, but of the hypothesized sign. Parental education is a particularly salient and significant predictor, and young women have better results than young men. In addition, being non-white appears to improve reported scores, though the standard error is just outside the 95 per cent bounds. This last result may reflect the strong aspirations for high academic performance in the English ethnic minorities, particularly among some groups. In the sample of 192 non-white students, 4 were Bangladeshi, 38 were Indian, and 24 Chinese, whereas 14 were black African and 8 black Caribbean and 4 were 'other black' (72 were of mixed parentage). If the sample is split into two variables representing Asian and black respondents respectively, and the models are re-rerun with the same variables, the coefficient on black is negative 
where the one on Asian is positive, which corresponds to literature that suggests that Asians differ from other minority groups in both their levels of performance and social capital (Sun 1998).

The discount factor has a positive sign, though is not significant, which may show that being able to defer gratification appears to generate higher academic performance as indicated by the theory. As predicted, the number of hours watching television significantly depresses academic performance or lower achievers watch more television, which may reflect a background disinclination or lack of incentive to do homework, but is a finding that adds to the public debate about the impact of television. The school climate variable does not perform well as it has a negative rather than the hypothesized positive sign, which is also non-significant; nor is there an indication that private schools have an impact.

Parental networks do not appear to help children's performance: the negative sign and the significance of the term shows that children with parents who know each other well do not perform so well as others at school. This suggests that not only does the Putnam-statement about the relative advantages of bridging versus bonding social capital hold, but that bonding social capital can worsen individual performance. This factor is explored more and discussed in models below. In this model religion is not a factor either. Trust independently affects academic performance, which shows that social capital can raise self-reported school performance, a factor the article explores and tests out more fully in the panel analysis below. Voluntary action does appear to have an effect as this variable is of positive sign and significant. In analysis not reported here, it is possible to run models with extracurricular activity as a variable. This term counts the number of school encouraged voluntary activities in a similar fashion to non-school voluntary activities, and in fact it is much like volunteering, and the two are correlated (Pearson=.42, sig at p.=.001). As such, for theoretical reasons and for model healthiness, it is not possible to run models with both extracurricular and 
volunteering. But whether run separately or as a combined variable, the results are much the same as those with just volunteering.

Model 2 controls for school-level measures of social capital in addition to the individuallevel scores. The coefficients and standard errors are not greatly changed by the addition of these variables. These results show the individual measures continue to predict performance even when the average level of performance has been controlled for at the school level. Both aggregate levels of trust and the membership of voluntary organizations do not significantly affect performance, but that school level networks increase it. Students in schools where friends' parents know each other do well, whereas having more parental friends individually depresses it. On the basis of these wave one results a student could be advised to join a school where parents' friends know each other but to ensure that his or her parents did not!

\section{Wave Two}

Moving to wave two, model 3 has many of the same variables as predictors, though with some questions repeated: the numbers of hours watching television, voluntary activities and trust. Because wave two has a different number of respondents, the summed variables reflecting parental involvement, socio-economic status and school climate have slightly different values. It is not possible to compare the coefficients between wave one and two because the dependent variables have different scales. Nonetheless, from inspection of the signs of Table 2 Model 3 and the probability levels, there is a similar pattern for socio-economic status, gender, the parental factors, the discount rate and the negative impact of the number of hours watching television. Private schools and school climate are not significant and act as controls on the model. Ethnicity is not significant, but religion is, which might reflect some differences between the reported grades in wave one and the actual scores in wave two: wave two is the final reward for the hard work put in 
Voluntary action is significant, though trust only reaches borderline significance. The network term retains its negative sign and significance, showing that the result holds up at the individual level in both waves. As in wave one, model 4 uses the new school-level variables as additional controls. This time school-level voluntary action is a significant predictor at the school level and the network term retains its negative importance, but with individual level trust falling out of the statistically acceptance range.

\section{The Change Model}

Tables 3 produces estimates of a random effects 'change model'. In model 1 the variables behave as before, with socio-economic status improving its probability score, with gender, parental education, television hours, parental involvement as significant factors. This time the discount factor moves into a statistically acceptable range, with ethnicity, school climate and private schools

proving to be non-significant. Again social networks is a negative predictor, and trust and voluntary action are positive and significant. As before, the school-level social capital variables are introduced in the second model. These controls only marginally affect impact of the individual-level variables but are not significant factors themselves. Thus the change model support s the basic inferences from the analysis of each wave.

\section{A Comparison With Published Examination Results}

To confirm the individual-level results, it is possible to analyze the published examination results available only at the school level, the percentage of students who obtain GCSEs. This part of the analysis uses the average responses of the students for voluntary action, trust and parental socializing networks and plots them against the per cent of GCSE passes for each school. Figures 2, 3 and 4 display the results, which show a strong relationship between performance and the average membership of voluntary groups, a weaker relationship with trust, and no observable relationship 
with networks, which replicates the results found in the survey analysis. Thus joining groups is clearly related to academic performance, which suggests that group membership enhances motivation; and trust seems to have the same effect. Social closure does not seem to have an effect at the school level, perhaps because it acts through different groups of students (see discussion below). Of course, the relationships that do exist may be a function of the social background of students: those from advantaged backgrounds may both perform and volunteer more. To control for social background a regression, using ordinary least squares as the estimator, takes GCSE results as the dependent variable, with the three social capital variables as independents. In addition, it adds a social-economic status variable, which is the schools' rank on its uptake of free school meals funded by the state, which is a powerful indicator of character the school intake. Table 4 produces the results: model 1 shows that voluntary action passes the significance test, with trust at near significance while the networks variable is not significant. Model 2 uses voluntary action as the social capital variable selected from model 1 with school meals as the control. Here both variables have the hypothesized signs and are significant in a model where these two variables explain most of the variation in the dependent term. Social capital, in the form of volunteering, remains as a determinant of school performance when accounting for the socio-economic status of the school intake.

\section{Why Do Networks Depress Performance?}

The puzzle of this article is that networks, which in theory could be a form of support for school-based work and a form of parental monitoring of student learning, are in this data a hindrance, perhaps showing that networks are not always beneficial, revealing how poor attitudes toward education can be transmitted among parents through their networks or bonding social capital. This result replicates Morgan and Sorensen’s (1999) finding that maths scores were negatively 
predicted by the strength of social closure amongst parents, what they associate with 'norm enforcing' instead of 'horizon-expanding' processes. Though their findings are controversial (Hallinan and Kubitschek 1999, Carbonaro 1999), the analysis here has replicated their results. Moreover, it the differences between networks and trust and group membership reveals the hypothesized distinction between the effects bonding and bridging social capital.

But it may be the case that different groups use bridging and bonding social capital in different ways. Families with lower socio-economic status may have less access to knowledge about academic performance and may not be able to transmit good education practice in their networks, whereas wealthier families may be able to transmit motivation and good practice in theirs. Thus the argument is that the impact of networks is mediated by SES. A re-estimated Table 2 model 2 can test this by adding to the existing model the interaction term SES*social networks, which is positive and significant (.1691, se $=.0561, \mathrm{p}=.003)$, which means that there is a positive interaction between higher SES and social networks over and above the individual impact of SES. The relationship that is also captured by the graph in figure 1, that shows the negative relationship for parental socializing for schools with low parental education students and the lack of a relationship for those with higher levels of parental education. It would seem that social networks do not on average benefit students, but they can be beneficial for higher socio-economic status or more highly educated families. It appears that the worse-off parents who have dense networks manage to worsen the performance of their offspring compared to similar parents who do not have those networks and even the better off parents who have the networks. 


\section{Conclusion}

It would be unwise for reformers to expect social capital to be a panacea for social ills, which may be applied liberally as an alternative or complement to market and New Public Management reforms. If it were such a simple relationship between performance and social factors, reformers would have latched on to the idea many years ago. Instead, there are several aspects to social capital, which takes different forms according the context in which it operates. Thus the central finding of this research is that some aspects of social capital predict academic success, but that not all aspects of bonding and networks are good for students. There are particular social pathways that affect student performance.

Parental networks can have a negative impact on performance, which extends a controversy begun in 1999, by including a different country, England, for the testing of the hypothesis, as well as an original measure of parental networks. Following Putnam and others, the research identifies the positive and negative aspects of social capital, and in particular negative aspects of bonding social capital. In education closed networks are only be advantageous if combined with positive attitudes toward study, perhaps through the norms of more highly educated and high SES families. The conclusion to draw is that social capital is thus not a simple good or nor has universal benefit - much depends on the context: the social good in question and the type of social capital that is available. Such a finding brings social capital research back closer to the discussion of unequal social and economic processes. Rather than being an independent factor, the impact of social capital is intimately bound up with the processes that generate inequalities in societies. 


\section{Tables}

\section{Table 1: Descriptive statistics}

Variable

$N$

Wave one

Academic proficiency

Socio-economic status

Parental education

Gender

Ethnicity

Hours watching television

Discount rate

Parental involvement

Private school

School climate

Friends' parents socialize

Religious

Trust

Voluntary action

Wave Two

Academic Proficiency

Hours watching television

Friends parents socialise

Trust

Voluntary action
1220

1249

1004

1247

1226

1242

1245

1240

1249

1247

1216

1236

1064

1248

682

672

672

615

678
Mean

3.3115

1.1789

.4203

.4627

.1378

2.6738

.1590

2.2016

.0777

2.2377

2.2582

.6019

4.9342

1.8173

5.946

2.251

2.2514

5.6488

1.3378
Standard

Deviation

.9288

.4167

.4938

.4988

.3449

.9771

.3658

.9495

.2677

.6801

1.1313

.4897

1.9590

1.6576

2.988

.9906

.9906

1.7217

1.3031
Mini Max

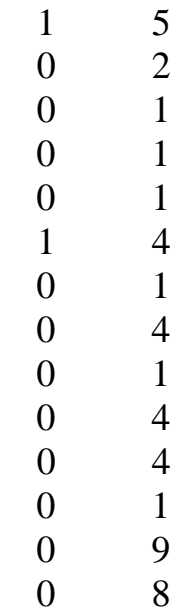

$\begin{array}{cc}0 & 12 \\ 1 & 4 \\ 1 & 4 \\ 0 & 9 \\ 0 & 8\end{array}$


Table 2: predictions of academic achievement, wave one and wave two

\begin{tabular}{|c|c|c|c|c|}
\hline & \multicolumn{2}{|c|}{ Wave 1} & \multicolumn{2}{|l|}{ Wave 2} \\
\hline & Model 1 & Model 2 & $\overline{\text { Model } 3}$ & Model 4 \\
\hline \multirow[t]{2}{*}{ Socio-economic status } & .0913 & .0968 & $1.3729 *$ & $1.1858 *$ \\
\hline & $(.0752)$ & $(.0755)$ & $(.2985)$ & $(.2964)$ \\
\hline \multirow[t]{2}{*}{ Parental education } & $.3268 *$ & $.3280^{*}$ & $.9144^{*}$ & $.7940 *$ \\
\hline & $(.0602)$ & $(.0597)$ & $(.2223)$ & $(.2236)$ \\
\hline \multirow[t]{2}{*}{ Gender } & $-.1873 *$ & $-.1773 *-$. & 7936* & $-.6639 *$ \\
\hline & $(.0606)$ & $(.0602)$ & $(.2361)$ & $(.2319)$ \\
\hline \multirow[t]{2}{*}{ Ethnicity } & .1662 & 1460 & -.1374 & -.2709 \\
\hline & $(.0864)$ & $(.0879)$ & $(.3091)$ & $(.3081)$ \\
\hline \multirow[t]{2}{*}{ Discount rate } & .1472 & -.1429 & $.6924^{*}$ & .6162 \\
\hline & $(.0791)$ & $(.0792)$ & $(.3236)$ & $(.3243)$ \\
\hline \multirow[t]{2}{*}{ Hours watching television } & $-.1387 *$ & $-.1344 *$ & $.3500 *-$ & $.3199 *$ \\
\hline & $(.0296)$ & $(.0300)$ & $(.1158)$ & $(.1168)$ \\
\hline \multirow[t]{2}{*}{ Parental involvement } & $.1434^{*}$ & $.1404^{*}$ & $.4084^{*}$ & $.3986^{*}$ \\
\hline & $(.0323)$ & $(.0324)$ & $(.1275)$ & $(.1280)$ \\
\hline \multirow[t]{2}{*}{ Private school } & .1180 & -.0131 & .1051 & -.2928 \\
\hline & $(.1890)$ & $(.1786)$ & $(.5838)$ & $(.5306)$ \\
\hline \multirow[t]{2}{*}{ School climate } & -.0112 & -.0136 & -.1004 & -.0796 \\
\hline & $(.0450)$ & $(.0449)$ & $(.1690)$ & $(.1667)$ \\
\hline \multirow[t]{2}{*}{ Religious } & .0400 & .0392 & $.7036^{*}$ & $.7425^{*}$ \\
\hline & $(.0600)$ & $(.0601)$ & $(.2354)$ & $(.2327)$ \\
\hline \multirow[t]{2}{*}{ Friends’ parents socialize } & $-.0765^{*}$ & $-.0770 *$ & $-.2414 *$ & $-.2540 *$ \\
\hline & $(.0255)$ & $(.0258)$ & $(.0934)$ & $(.1004)$ \\
\hline \multirow[t]{2}{*}{ Trust } & $.0543^{*}$ & $.0553^{*}$ & 0871 & .0777 \\
\hline & $(.0185)$ & $(.0178)$ & $(.0719)$ & $(.0678)$ \\
\hline \multirow[t]{2}{*}{ Voluntary action } & $.0606 *$ & $.0546 *$ & $.2411^{*}$ & .1407 \\
\hline & $(.0197)$ & $(.0215)$ & $(.1163)$ & $(.0842)$ \\
\hline \multirow[t]{2}{*}{ Socialize (school) } & & $.2281^{*}$ & & -.1696 \\
\hline & & $(.0975)$ & & $(.4450)$ \\
\hline \multirow[t]{2}{*}{ Trust (school) } & & .0135 & & $.9277^{*}$ \\
\hline & & $(.0770)$ & & $(.3461)$ \\
\hline \multirow[t]{2}{*}{ Voluntary Action (school) } & & $.2505^{*}$ & & 1.1407 \\
\hline & & $(.1190)$ & & $(.6638)$ \\
\hline \multirow[t]{2}{*}{ Constant } & 3.1203 & 2.1542 & 2.6473 & -3.1845 \\
\hline & $(.1853)$ & $(.4579)$ & $(.9622)$ & $(2.1777)$ \\
\hline \multirow[t]{2}{*}{ Variance at level 1} & .5452 & .5456 & $4.407 \mathrm{e}-07$ & 4.5323 \\
\hline & $(.0283)$ & $(.0283)$ & (6.295e-06) & $(.3057)$ \\
\hline \multicolumn{5}{|c|}{ Variances of random effects at level 2: } \\
\hline \multirow[t]{2}{*}{ (intercept) } & .0003 & .0006 & 4.4524 & .0252 \\
\hline & $(.0011)$ & $(.0014)$ & $(.3079)$ & $(.0519)$ \\
\hline \multirow[t]{2}{*}{ (slope) } & .0479 & .0674 & .3506 & .0003 \\
\hline & $(.0358)$ & $(.0859)$ & $(.4002)$ & $(.0167)$ \\
\hline Loglikelihood & -914.6909 & -911.5173 & -1041.1653 & -1033.3387 \\
\hline $\mathrm{N}$ & 797 & 797 & 471 & 471 \\
\hline
\end{tabular}

*= p. $<.05$, standard errors in parentheses 
Table 3: change model of academic achievement

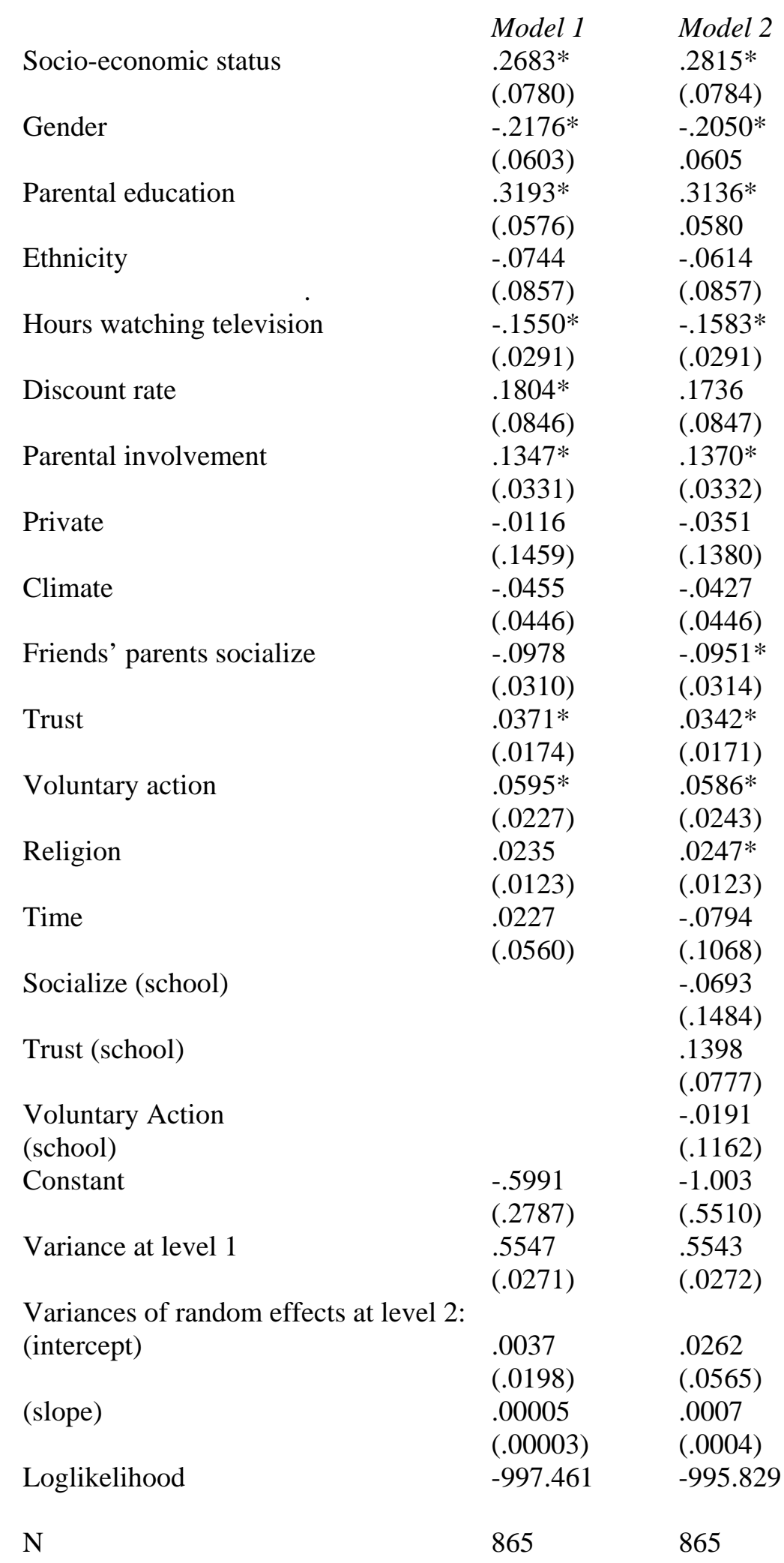


Table 4: OLS regression of school per cent GCSE 2000 scores

$\begin{array}{lll} & \text { Model 1 } & \text { Model } 2^{5} \\ \text { Voluntary action } & \begin{array}{l}29.980^{*} \\ (5.567)\end{array} & \begin{array}{l}14.941^{*} \\ (6.527)\end{array} \\ \text { Trust } & \begin{array}{l}7.267 \\ (3.724)\end{array} & \\ \text { Parents' Socialize } & \begin{array}{l}3.749 \\ (5.177)\end{array} & \\ \text { School Meals } & - & .539^{*} \\ & & (.143) \\ \text { Constant } & 37.167 & 52.786 \\ & (20.843) & (16.704) \\ \text { R-square } & .643 & .768 \\ \text { N } & 27 & 24\end{array}$

${ }^{5}$. The number of cases in model two reduces by three because data are not available for private school. 
Figure 1: School GCSE results (per cents)

by mean membership of voluntary groups

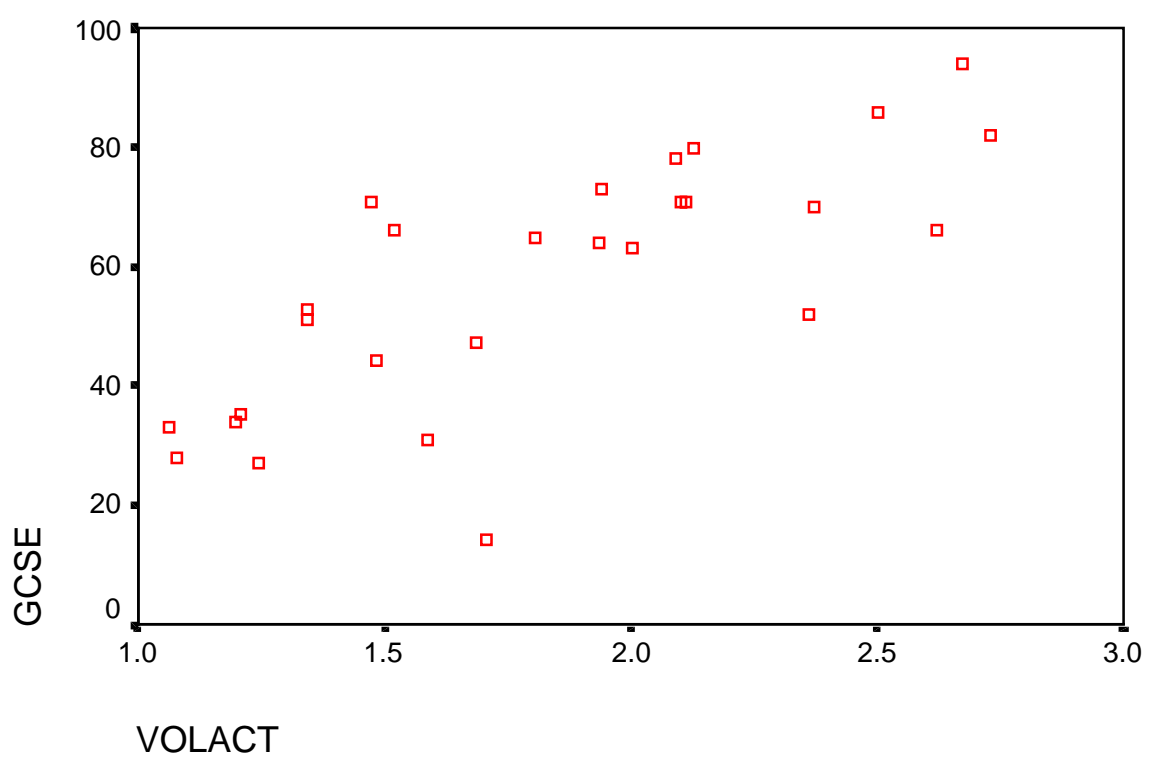

Figure 2: School GCSE results by mean of sumtrust

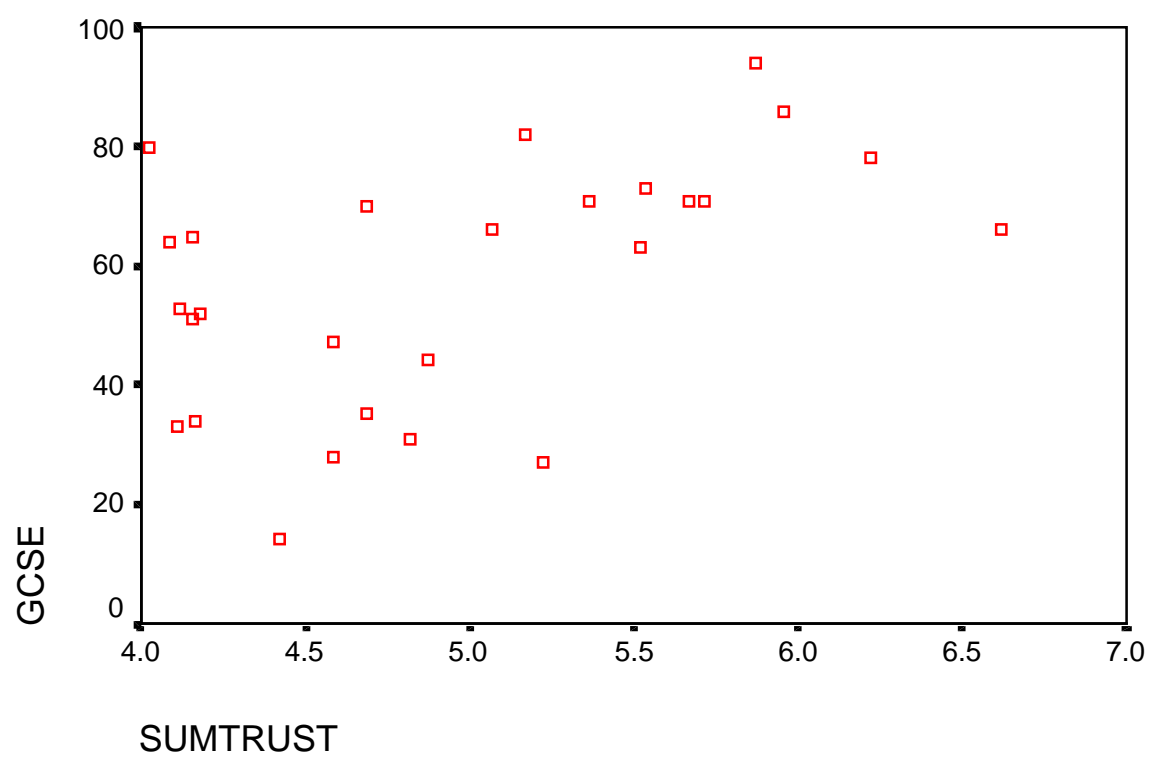


Figure 3: School GCSE results by mean of social networks

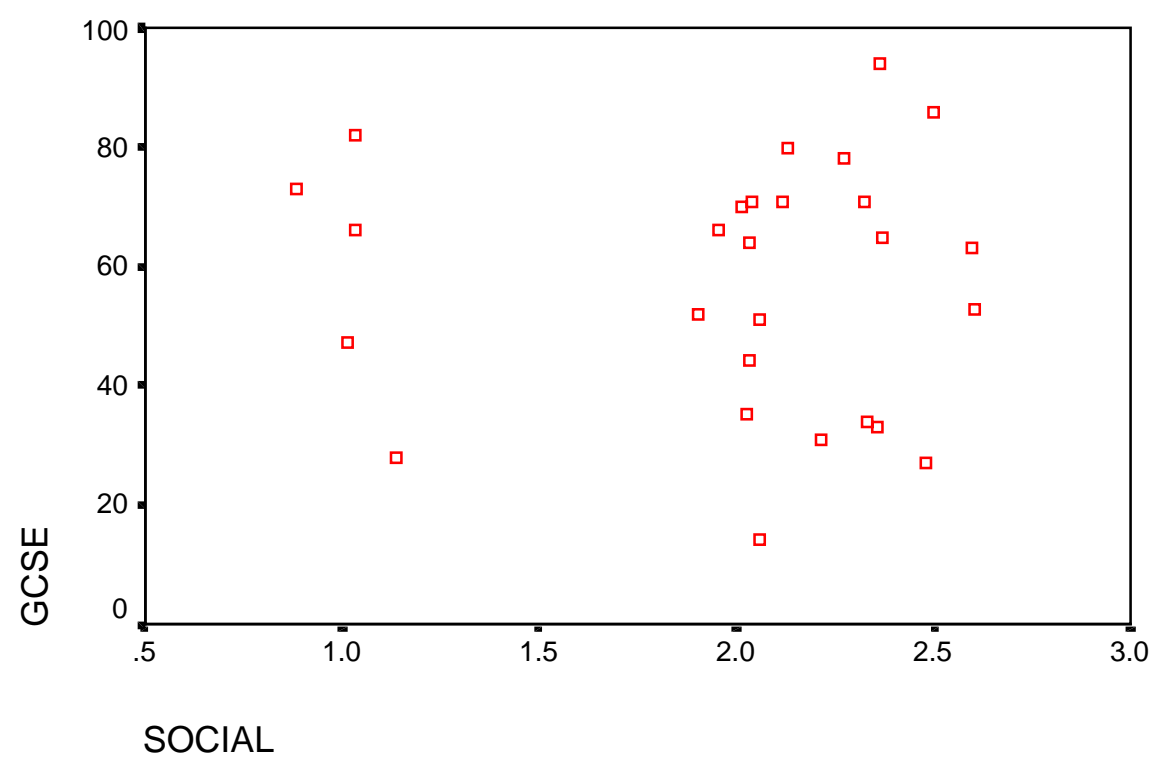


Figure 4. Individual academic performance by proportion of parents within school with degrees (network academic ability) by frequency of parents socializing with each other (student reported network closure)

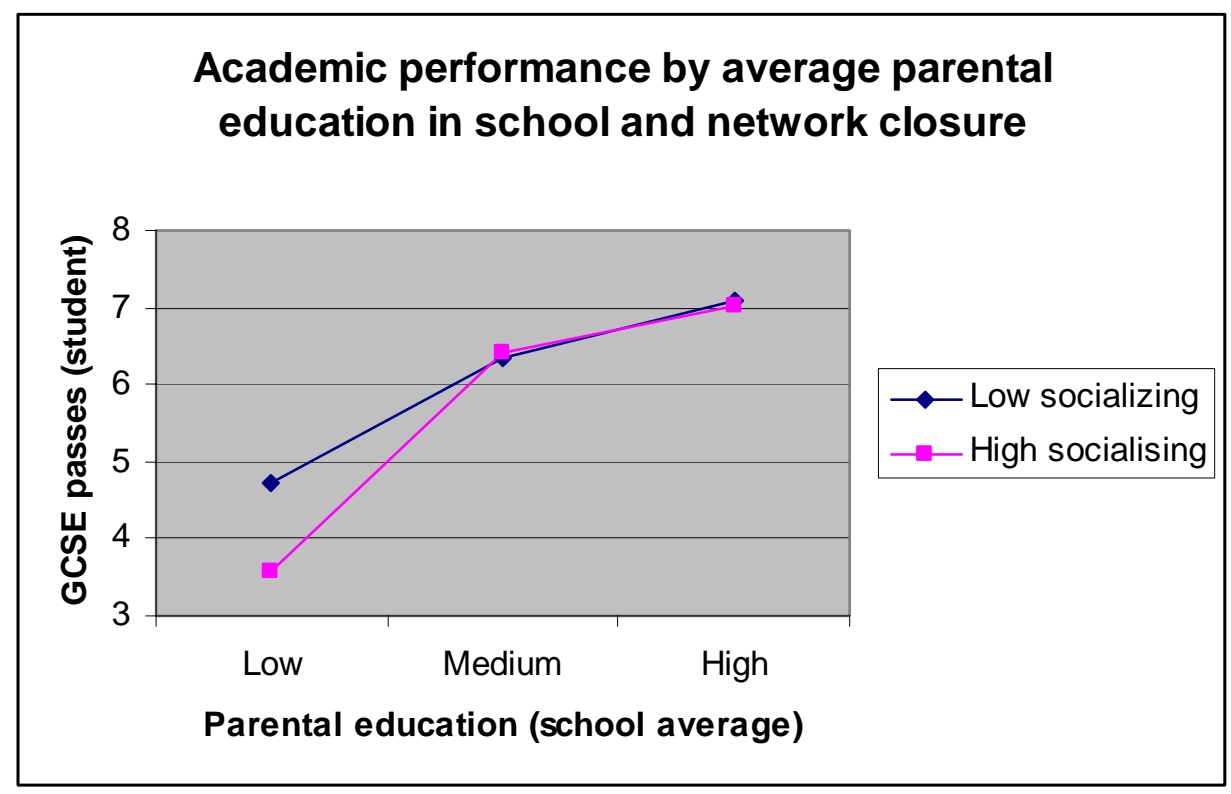




\section{References}

Anderson, D. R. and Collins, P. (1988), The Impact on Children's Education: Television Impact on Cognitive Development (Washington DC: Department of Education).

Arnot, M. (1998), Recent Research on Gender and Educational Performance (London: HMSO). Ashworth, L. (1995), Children's Voices in School Matters: a Report of an ACE Survey into School Democracy (London: ACE).

Baerveldt, C., Van Rossem, R., \& Vermande, M.M. (2003). “Pupils' delinquency and their social networks. A test of some network assumptions of the ability and inability models of delinquency”. The Netherlands' Journal of Social Sciences, 39(2), 107-125

Beck, P. and Jennings, M. (1982), "Pathways to participation” American Political Science Review, 76, pp. 94-108.

Bohte, J. and Meier, K..(2001), "Structure and the Performance of Public Organizations: Task Difficulty and Span of Control", Public Organization Review 1 (Number 3), 341-354.

John Bohte (2005), 'School bureaucracy and student performance at the local level." Public Administration Review, forthcoming.

Carbonaro, W. (1999), “Opening the debate on closure and schooling outcomes: comment on Morgan and Sorensen” American Sociological Review 64, pp. 682-6.

Coleman, J. and Hoffer, T. (1987), Public and Private Schools: the Impact of Communities (New York: Basic Books).

Coleman, J., Campbell, C., McPartland, J, Mood, A., Weifeld and York, R. (1966), Equality of Educational Opportunity (Washington, DC: US Department of Health, Education and Welfare). Coleman, J., Hoffer, T. and Kilgore, S. (1982a), 'Cognitive outcomes in public and private schools’, Sociology of Education, 55, pp. 65-76. 
Coleman, J., Hoffer, T. and Kilgore, S. (1982b), High School Achievement: Public, Catholic and Private Schools Compare (New York: Basic Books).

Gambetta, Diego (1993) The Sicilian Mafia: The Business of Private Protection (Cambridge, MA: Harvard University Press).

Goldstein, H. (1995), Multilevel Statistical Models (London: Edward Arnold).

Goldstein, H., Rabash, J.,Yang, M. \& Woodhouse, G. et al (1993), “A multilevel analysis of school examination results”, Oxford Review of Education 19, pp. 425-433.

Granovetter, M. (1973), “The Strength of Weak Ties”, American Journal of Sociology, 78, pp. 13601380.

Haensly, P., Lupowski, A. and Edlind, E. (1985), “The role of extracurricular activities in education” The High School Journal pp.110-490.

Hallinan, Maureen T. and Warren N. Kubitschek (1999), “Conceptualizing and measuring school social networks: Comment on Morgan and Sørensen” American Sociological Review 64, pp. 687693.

Halpern, D. (2001), “Moral values, social trust and inequality. Can values explain crime?” British Journal of Criminology 41, pp. 236-251.

Hero, R. (2003), 'Social capital and racial inequality in America', Perspectives on Politics, 1: 113122.

Ho, E. and Willms, J. (1996), "Effects of parental involvement on eight grade achievement” Sociology of Education 69, pp. 126-41.

Hooghe, M. and Stolle, D. (2002), "The roots of social capital: the effect of youth experiences on participation and values in adult life” paper to the American Political Science Association meeting, Boston. 
Hox, J. (2002), Multilevel Analysis (Mahway, NJ: Lawrence Erlbaum Associates).

Knack, S. and P. Keefer (1997), "Does social capital have an economic pay-off? A cross country investigation” Quarterly Journal of Economics 112, pp. 1251-1288.

Kreft, I. (1993), "Using multilevel analysis to assess school effectiveness: a study of Dutch secondary schools” Sociology of Education 66, pp. 104-29.

Kreft, I. and Leeuw, J. de (1998), Introducing Multilevel Modeling (London: Sage).

Linn, M. C. and Hyde, J. (1989), “Gender, mathematics and science”, Educational Research, 18, pp. $17-27$.

Lehrer, E. L. (1999). "Religion as a determinant of educational attainment: an economic perspective” Social Science Research 28, pp. 358-379.

Meier, K. and O’Toole, L. (2001),'Managerial strategies and behavior in networks: a model with evidence from public education , Journal of Public Administration Research and Theory, 11(July 2001), pp. 271-295.

Meier, K. and O’Toole, L. (2004), 'Public management in intergovernmental networks: matching structural and behavioral networks,” Journal of Public Administration Research and Theory 14, 4 (October 2004): 469-94.

Meier, K. and O’Toole, L. (2005), 'Public management and educational performance: the impact of managerial networking', Public Administration Review, 7, 1 (2005): pp. 45-68.

Meier, K. Wrinkle, R, and Polinard, J.L..(2000), "Bureaucracy and Organizational Performance: Causality Arguments about Publics Schools." American Journal of Political Science 44, 590-603. Mischel, W. (1958), "Preference for delayed reinforcement: an experimental study of a cultural observation” Political Psychology 95, pp. 57-61. 
Mischel, W. (1960), “Preference for delayed reinforcement and social responsibility” Journal of Abnormal and Social Psychology 62, pp. 1-7.

Milward, H. and Provan, K. (2000), 'How networks are governed', in C. Heinrich and Laurence Lynn (eds.), Governance and Performance, Washington DC:Georgetown University Press.

Morgan, S. and Sørensen, A. (1999), "Parental networks, social closure, and mathematics learning: a test of Coleman's social capital explanation of school effects” American Sociological Review 64, pp. 661-681.

Nichols, J. D. and White, J. (2001). "Impact of peer networks on achievement of high school algebra students”, The Journal of Educational Research; 94, 267-75.

OECD (2002), The Well-Being of Nations: The Role of Human and Social Capital (Paris: OECD).

\section{http://www.oecd.org/els/pdfs/EDSMINDOCA003.pdfT.}

Performance and Innovation Unit (PIU) (2002), Social Capital A Discussion Paper. (London, Cabinet Office).

Putnam, R. (1993), Making Democracy Work. (Princeton: Princeton University Press).

Putnam, R. (2000), Bowling Alone (New York: Simon and Schuster).

Rabe-Hesketh, S., Sckondral, A. and Pickles, A. (2002), 'Reliable estimation of generalized linear mixed models using adaptive quadrature’, The Stata Journal, 2(1), 1-21.

Rabe-Hesketh, S., Pickles, A. and Skrondal, A. (2004), GLLAMM Manual. Berkeley Division of Biostats Working Paper Series. Working Paper 160.

Regnerus, M. D. and Elder, G. (2001). "Staying on Track in School: Religious Influences in High and Low-Risk Settings." Carolina Population Center: UNC, Chapel Hill, Carolina Population Center. Rice, T. and Sumberg, A. (1997), “Civic culture and performance in the American states” Publius 27, pp. 99-114. 
Sandler, W. (1996), “Catholic schools and academic achievement” Journal of Human Resources 31, pp. pp. 540-48.

Schneider, M. Scholz, J. Lubell, M. Mindruta, D. and Edwardsen, M.(2003). "Building Consensual Institutions: Networks and the National Estuary Program." American Journal of Political Science 47 (1): 143-158.

Schneider, M., Teske, P. and Marschall, M. (2000), Choosing Schools: Consumer Choice and the Quality of American School. Princeton: Princeton University Press.

Smith, E. (1999), "The effects of investment in the social capital of youth on political and civic behaviour in young adulthood: a longitudinal analysis” Political Psychology 19, pp. 749-779.

Smith, K. and Larimer, C.(2004), 'A mixed relationship: bureaucracy and school performance’, Public Aministration Review, 64, 728-736.

Sobel, J. (2002), ‘Can we trust social capital?’, Journal of Economic Letters, XL, 139-154.

Steinberg, L. (1996), Beyond the Classroom: Why School Reform Has Failed and What Parents Need to Do (New York: Simon and Schuster).

Stolle, D. (2001), “'Getting to trust' An analysis of the importance of institutions, families, personal experiences and group membership” in Dekker, P. and Uslaner, E. (Eds.), Social Capital and Participation in Everyday Life (London: Routledge).

Sun, Y. (1998), “The academic success of East-Asian-American students: an investment model” Social Science Research 27, pp. 432-56.

Sun, Y. (1999), "The contextual effects of community social capital on academic performance”, Social Science Research 28, pp. 403-426.

Usalaner, E. (2001), “How trust and religion shape civic participation”, in Dekker, P. and Uslaner, E. (Eds.) Social Capital and Participation in Everyday Life (London: Routledge). 
Uslaner, E. (2004), 'Trust and social bonds: faith in others and policy outcomes reconsidered', Political Research Quarterly, 57, 501-7.

Valenzuela, A. and Dornbusch, S. (1994), "Familiarism and social capital in the academic achievement of Mexican-origin and Anglo high school adolescents” Social Science Quarterly 75, pp. $18-36$.

Whiteley, P. (2000), “Economic growth and social capital” Political Studies, 48, pp. 443-466

Zellner, A. (1962), “An efficient method for estimating seemingly unrelated regressions and tests for aggregation bias”, Journal of the American Statistical Association, 57, pp. 348-368. 


\section{Appendix: Coding of the variables}

Academic Proficiency - 1=Es or below, 2=Ds, 3=Cs, 4=Bs 5=As; too varied to say=3 (v4)

Cars $0=$ none, $1=$ one; $2=2+\mathrm{dk}=$ missing (v3)

Consult - Consulted about school rules $\quad 0=$ none; $1=$ not much; $2=$ a little; $3=$ =quite a bit; $4=$ a lot (v33)

Discount Rate - discount rate $0=\mathrm{I}$ would rather get $£ 100$ right now; $1=\mathrm{I}$ ॥| would rather wait one whole month and get $£ 150$.

Ethnicity $-1=$ non white; $0=$ white.

Express - Teachers invite the expression of opinions $0=$ never; $1=$ very occasionally; $2=$ not very often; $3=$ often; $4=$ very often.

Friends Parents Socialize - parents socialize with friends' parents $0=$ never; $1=$ =very occasionally; $2=$ not very often; $3=$ often; $4=$ very often.

Gender - 0=girl 1=boy.

Hobby - taken part in school hobby or interest clubs.

Owner $1=$ own own home; $0=$ if not.

Parental Education 1=if parents went to university or higher education; 0=did not go to university or polytechnic.

Pareve - parents come to school for parents' evening - $0=$ never; $1=$ very occasionally; $2=$ not very often; $3=$ often; $4=$ very often, $\mathrm{dk}=0$.

Parfund - parents come to school for fundraising activities $0=$ never, $1=$ very occasionally, $2=$ not very often; $3=$ often; $4=$ very often $\mathrm{dk}=0$.

Parental involvement - underlying variable saved from alpha of pareve and parfund

Partime - have time employment $0=$ no; $1=$ yes.

Private school - school type 0 =state funded school; 1 = privately funded school.

Voluntary action - participation in voluntary projects - adds together scores for participation in fundraising, petitions, rangers, religious projects, election campaigns, helping elderly, environmental projects, charities, demonstrations and other voluntary activities.

Religion $-1=$ religious; $0=$ not 
Sayclass Say in what you do in class $0=$ none at all; $1=$ not much; $2=$ some; $3=$ quite a bit; $4=a$ lot School Climate - summary variable from teachers, express, sayclass, consult

Socio economic status - summary variable from cars and owner

Socialize - parents socialize with friends’ parents $0=$ never; $1=$ very occasionally; $2=$ not very often; 3=often; 4=very often

Sports Taken part in school sport team $0=$ no; $1=$ yes

Trust - adds together positive scores (1) for trust in school, neighbors and adults

Hours Watching TV - numbers of hours of television watched per day $1=0-1$ hours a day; $2=1-2$ hours a day; $3=2-3$ hours a day; $4=$ more than three hours a day.

Teachers - teachers work well or badly -2=very badly; -1=badly; $0=$ neither; $1=$ =well; 2=very well.

Trust in School - How much students trust others in school class $0=$ not at all; $1=$ not very much; $2=$ quite a lot; $3=$ a great deal ...

Trust in Neighbors - How much students trust most of your neighbors $0=$ not at all; $1=$ not very much; $2=$ quite a lot; $3=$ a great deal ...

Trust in Adults In School - How much students trust 0=not at all; 1=not very much; 2=quite a lot; $3=$ a great deal ... 